\title{
FORUM
}

\section{Transgenic Mosquitoes for Malaria Control: Progresses and Challenges}

\author{
Ludiano A. Moreira ${ }^{1}$ And Marcelo Jacobs-LorenA ${ }^{2}$ \\ ${ }^{1}$ Centro de Pesquisas René Rachou - Fiocruz, Laboratório de Malária, Av. Augusto de Lima, 1715, Barro Preto \\ 30190-002, Belo Horizonte, MG, Brazil \\ ${ }^{2}$ Johns Hopkins School of Public Health, Department of Molecular Microbiology and Immunology, Malaria Research \\ Institute, 615 North Wolfe St, E5132 Baltimore, MD, 21205 USA
}

Neotropical Entomology 32(4):531-536 (2003)

Mosquitos Transgênicos Para o Controle da Malária: Progressos e Desafios

\begin{abstract}
RESUMO - A malária mata milhões de pessoas a cada ano e as estratégias atuais de controle da doença, como inseticidas e drogas não têm sido tão eficientes. Por este motivo, novos meios para o combate à malária são de extrema importância. Avanços no estudo do mosquito vetor e sua interação com o parasito da malária fizeram os cientistas pensarem que é possível a manipulação genética dos mosquitos para torná-los vetores ineficientes. Neste artigo, revisamos os avanços na introdução de genes exógenos na linhagem germinativa de mosquitos, a caracterização de promotores específicos de certos tecidos, a identificação de produtos gênicos que bloqueiam o parasita no mosquito, bem como discutimos a recente geração de mosquitos transgênicos, menos eficientes na transmissão de malária. Enquanto muitos progressos foram obtidos, muitos anos de pesquisa são ainda necessários para que mosquitos transgênicos possam ser utilizados na natureza.
\end{abstract}

PALAVRAS-CHAVE: Malária, transgenia, bloqueio da transmissão, Plasmodium

ABSTRACT - Malaria kills millions of people every year and the current strategies to control the disease, such as insecticides and drugs have not been completely efficient. Because of that, novel means to fight against malaria are of utmost importance. Advances in the study of the mosquito vector and its interactions with the malaria parasite made scientists think that it is possible to genetically manipulate the mosquitoes to make them inefficient vectors. Here we review the advances on the introduction of foreign genes into the mosquito germ line, the characterization of tissue-specific promoters, the identification of gene products that block development of the parasite in the mosquito, and we discuss the recent generation of transgenic mosquitoes impaired for malaria transmission. While much progress has been made, many years of research are still needed before transgenic mosquitoes can be used in the field.

KEY WORDS: Malaria, transgenesis, transmission blocking, Plasmodium

Malaria is responsible for causing high morbidity and mortality in poor countries mainly in African children under the age of five (200 to 450 million cases per year). These numbers are likely to double by 2020 if no serious control programs are applied (Breman 2001). Over the last 20 years, morbidity and mortality from malaria have been increasing due to precarious health systems, antimalarial drugs and insecticide resistances, changes in weather patterns, human migration, population displacement (World Bank Report 2001) and the lack of an efficient malaria vaccine. In Brazil, in 1999 and 2000, the Health Ministry reported more than 600,000 cases, in malaria endemic areas (FUNASA 2002).

Concrete actions need to be sought in order to reduce the malaria burden. This has to be a multidisciplinary effort because no single control measure is sufficient. The use of multiple complementary strategies offers the most promising approach. Mosquitoes are the obligatory vectors of malaria parasites. After a blood meal, the parasite undergoes an intricate development cycle that involves mating of the gametes, transformation into the motile ookinete, formation of the oocyst and its burst into thousands of sporozoites that colonize the mosquito salivary glands (Ghosh et al. 2000). If the mosquito is able to block any of this developmental stages the Plasmodium cycle is interrupted and less malaria transmission would be expected.

Within this thought, the genetic modification of mosquitoes to reduce their ability to transmit the disease is a strategy that needs to be further explored. For that to be accomplished several barriers need to be overcome. Methodologies to introduce foreign genes into vector 
mosquitoes (e.g., via transposable elements) have to be developed, promoters that can drive the expression of foreign genes in the correct tissues and at the appropriate times need to be characterized and importantly, "blocking" gene products capable of interfering with parasite development in the mosquito must be discovered. Here we review the progresses and challenges based on this strategy.

\section{Overview of the Mosquito Transformation}

More than two decades ago, Rubin \& Spradling (1982) published the first demonstration of the genetic transformation of an insect. They showed that the $P$ transposable element could be used to introduce foreign genes into the germ line of Drosophila. Unfortunately, after many years of trials in other systems the conclusion was that this vector could only be used to transform organisms belonging to Drosophila genus. This resulted in considerable delays toward the germ line transformation of nondrosophilids. Actually, the first reported case of mosquito transformation used the $P$ vector (the same transposon) (Miller et al. 1987), but analysis of the transformants indicated that it happened by chance, rather than by a $P$ transposasemediated event. It is possible that the published $P$ elementmediated transformation of Aedes aegypti L. (Morris et al. 1989) and A. triseriatus (Say) (McGrane et al. 1988) was also due to the same fortuitous event. The fact is that only after 14 years since the report by Miller et al. (1987) the stable transformation of Anopheles gambiae (Giles) was achieved (Grossman et al. 2001).

Like $P$ element, other transposon-based vectors have proved their usefulness in specific species because their function differs in diverse cellular environments, and perhaps in response to differing genomic organization (Handler 2000). Transposons are DNA sequences able to recognize host specific sequences (in our case mosquito), cut at that point and insert themselves repeatedly into different chromosome locations if they also have active encoding transposase (for review see Atkinson et al. 2001). By genetic engineering it was possible to delete the transposase encoding gene from the transposon and express it via a "helper" plasmid. With that, upon integration, the transgene is fixed into the insect genome.

The transformation technique involves the microinjection of the recombinant DNA into the posterior end of mosquito embryos (fresh laid eggs) prior to pole cell formation (Morris 1997).

For insects, the most important transposable elements for their transformation success were: Hermes from Musca domestica L. (Warren et al. 1994) used to transform A. aegypti (Jasinskiene et al. 1998, Kokoza et al. 2000, Moreira et al. 2000, Pinkerton et al. 2000), mariner or Mos1 from Drosophila mauritiana Tsacas \& David (Medhora et al. 1991) for A. aegypti transformation (Coates et al. 1998, Moreira et al. 2000); Minos from Drosophila hydei Sturtevant (Franz \& Savakis, 1991) used to transform Anopheles stephensi Liston (Catteruccia et al. 2000) and piggyBac from Trichoplusia ni Hübner (Cary et al. 1989) that has been shown to be very promiscuous in a number of insect orders and also mosquito species [for $A$. aegypti (Kokoza et al. 2001), for Culex quinquefasciatus Say
(Allen et al. 2001), for A. stephensi (Ito et al. 2002, Moreira et al. 2002, Nolan et al. 2002), for A. gambiae (Grossman et al. 2001) and more recently for Anopheles albimanus Wiedemann (Perera et al. 2002)].

These vectors have advantages and disadvantages: Hermes, for instance, has a different transposition behavior in mosquitoes because upon integration plasmid flanking sequences are also incorporated into the recipient genome (Jasinskiene et al. 1998, 2000, Pinkerton et al. 2000, Allen et al. 2001); piggyBac has been shown to precisely integrate into the recipient genome at TTAA sequence sites (Cary et al. 1989). Because of its wide functionality in many insect species, its high transformation rates (up to 60\% in Coleoptera, Berghammer et al. 1999) and the perfect integration (Grossman et al. 2000, 2001; Kokoza et al. 2001; Nolan et al. 2002) piggyBac seems to have advantages over the others cited above.

\section{How to Detect Transformants?}

The first published studies on the transformation of mosquitoes used insecticide and antibiotic resistance genes as markers (Miller et al. 1987, McGrane et al.1988, Morris et al. 1989). Later it was concluded that these markers could generate false positives when screening for transformants. The use of genes to rescue a mutation of an eye color gene proved to be far superior and very successful in Drosophila. A great discovery was that the Drosophila cinnabar gene encoding the kynurenine hydroxylase could rescue the $A$. aegypti white eye color mutation (Cornel et al. 1997). Using this eye color marker Coates et al. $(1998,1999)$ and Jasinskiene et al. (1998) first reported the stable transformation of $A$. aegypti using Hermes and mariner transposable elements and until recently this marker has been used. Although efficient, this approach could only be used for organisms, in which an eye color mutant and a clone of the corresponding wild type gene were available, which is rare in mosquitoes.

A major advance on the technique wich the use of the green fluorescent protein (GFP), cloned from a jellyfish, as a marker for insect transformation. GFP driven by a Drosophila actin promoter was first used for $A$. aegypti (Pinkerton et al. 2000). Besides being universal, GFP has the advantage that transformants can already be detected at larval stages. GFP constructs driven by the polyubiquitin (Handler \& Harrell 1999, Perera et al. 2002) and PAX eye-specific (Horn et al. 2000, Kokoza et al. 2001, Ito et al. 2002, Moreira et al. 2002) promoters have also been tested. Among these, the eyespecific promoter is more suitable because as the GFP expression occurs only in eye tissues it may reduce possible toxic effects of this protein (Fig. 1). GFP is being the most preferred marker and has been used for A. aegypti (Pinkerton et al. 2000, Kokoza et al. 2001), C. quinquefasciatus (Allen et al. 2001), A. stephensi (Catteruccia et al. 2000, Ito et al. 2002, Moreira et al. 2002), A. gambiae (Grossman et al. 2001) and A. albimanus (Perera et al. 2002).

\section{How to Drive the Expression of a Transgene?}

For a foreign gene to be expressed it is necessary the action of a promoter sequence. Whenever possible it is advantageous 

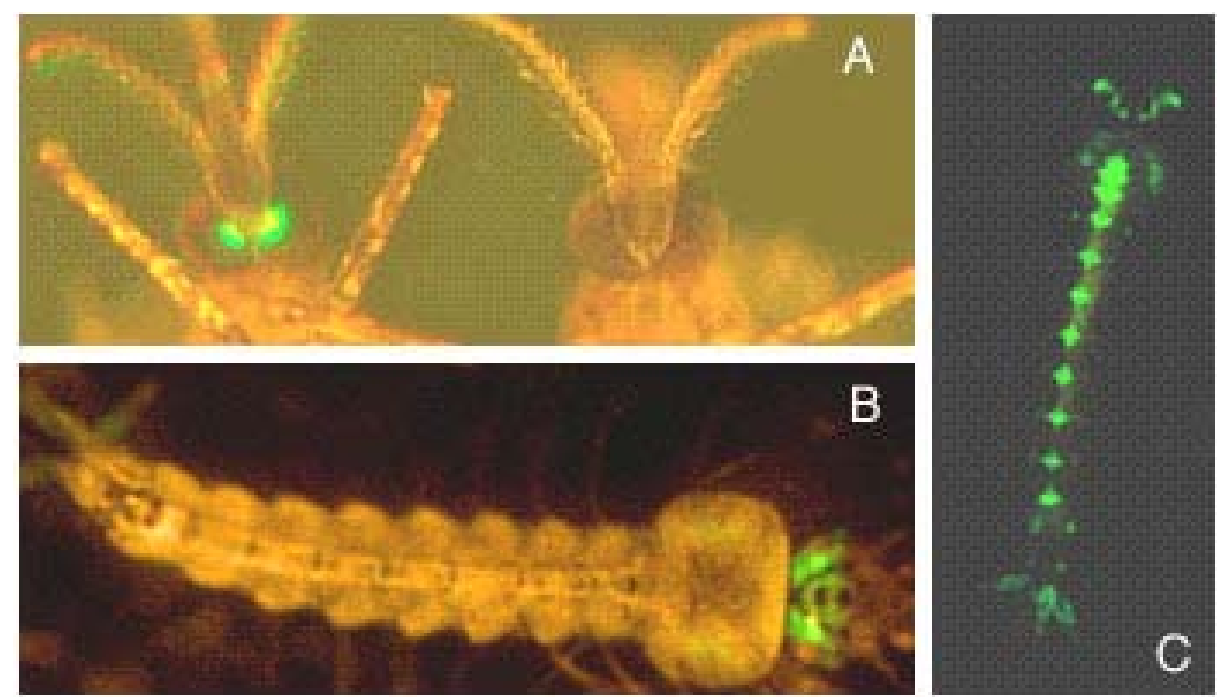

Figure 1. Green fluorescent protein (EGFP) expression on transgenic mosquitoes using the pBac[3xP3-EGFP afm] transposable element. A) Transgenic mosquito head on the left and a non-transgenic mosquito on the right side; B) Dorsal pattern expression of EGFP on a transgenic larva; C) Ventral pattern expression of EGFP of a transgenic larva seen only under fluorescent light.

that the promoter will drive the expression of the transgene in a tissue and time specific manner. For example, in the case of the malaria parasite, as the gametocytes and ookinetes are inside the gut lumen, a gut specific promoter would be more suitable for secretion of the gene product just after a blood meal. On the other hand, to target sporozoites it would be interesting to have a fat body or salivary gland specific promoter. In theory, ubiquitous promoters that are active in all tissues and at all times, should also be useful, although one should concern about the possible fitness problems that this generalized expression would place on the mosquito.

In order to target sporozoites in salivary glands, Coates et al. (1999) studied putative Apyrase and Maltase-like I promoter sequences from $A$. aegypti, in transgenic mosquitoes. Although they detected tissue, temporal and sex specificity, the expression was somehow weak, limiting the use of these promoters for driving the expression of antiparasitic transgenes.

Kokoza et al. (2000) used the A. aegypti vitellogenin promoter to drive a strong expression of the mosquito defensin (an antibacterial peptide) in the hemolymph of transgenic $A$. aegypti females. In the mosquito midgut, Moreira et al. (2000) demonstrated that both $A$. gambiae and $A$. aegypti carboxypeptidases promoters (Edwards et al. 1997, 2000) could drive strong blood-inducible transgene expression in transgenic $A$. aegypti. Expression was tissue, temporal and sex specific. Even though these two species have a very distant evolutionary relation (Service, 1993) the promoter functionality on both species suggests strong conservation of the carboxypeptidase regulatory sequences.

\section{Anti-Parasitic Genes}

The discovery and characterization of an anti-parasitic gene to interfere with the parasite development in the mosquito are very important before one wants to generate a "nonvector mosquito". Although there are many candidate genes available from different species, any deleterious effect of these gene products on the mosquito should be avoided.

Kokoza et al. (2000) produced transgenic A. aegypti that over expressed its defensin gene driven by a vitellogenin promoter. This defensin was active against bacteria and stable in the mosquito haemolymph for almost three weeks after a single blood meal, although it was not tested against Plasmodium spp.

In an attempt to find the ligands and/or receptors that are responsible for the recognition/invasion of the mosquito midgut and salivary glands by the parasite Ghosh et al. (2001) screened a phage display library. By doing that they identified a peptide (SM1) that binds specifically to the midgut lumen and the salivary glands, but not to other tissues. Furthermore, when they tested against Plasmodium berghei Vincke \& Lips in $A$. stephensi, the SM1 inhibited ookinete invasion of the midgut and sporozoite penetration to the salivary glands $(89 \%$ to $100 \%$ ). The next step was to construct a hybrid gene to express a SM1 tetramer in transgenic mosquitoes. Ito et al. (2002) used the carboxypeptidase promoter and its secretory signal sequence to drive this tetramer in transgenic $A$. stephensi. The transformed mosquitoes indeed expressed the transgene and effectively inhibited oocyst formation (69\% to 95\%) after feeding on infected mice. Most important was that transgenic mosquitoes reduced the capability to transmit the parasite to non-infected mice. Indeed, transmission was completely blocked in two out of three experiments and in a third transmission was greatly reduced. This work was the first demonstration that it is possible to genetically modify and disable anopheline mosquitoes from being efficient vectors.

Zieler et al. (2001) worked with different sources of phospholipases A2 (PLA2) and found that particularly the venom PLA2s were able to block the Plasmodium 
development inside the mosquito. The mechanism of action was unclear but probably the venom PLA2s, with their membrane inserting capability, would mask the receptors on the midgut epithelia that the parasite uses to recognize and invade it. Using one of this anti-parasite molecule Moreira et al. (2002) transformed A. stephensi with a construct similar to the one used by Ito et al. (2002) but instead of the SM1 tetramer they placed the bee venom PLA2 coding region. They detected PLA2 mRNA specifically in the guts of transgenic mosquitoes, what would be expected when using a gut specific promoter. It was also possible to detect the transgenic protein by Western blot and immunofluorescence analysis. Moreover, when transgenic mosquitoes fed on Plasmodium berghei infected mice, they had, on average, $87 \%$ less oocysts in comparison to the control mosquitoes. Parasite transmission to naïve mice was greatly reduced (Moreira et al. 2002).

In a different approach with the use of a Sindbis virus vector Capurro et al. (2000) expressed, in mosquitoes, a single chain antibody against Plasmodium circumsporozoite protein (CSP). When Aedes mosquitoes expressed this molecule, invasion of $P$. gallinaceum sporozoites on salivary glands was strongly inhibited (96.8\% to $99.9 \%$ ). This is a promising candidate for the stable generation of refractory transgenic mosquitoes. Another alternative candidate for transmission blocking was proposed by Yoshida et al. (1999), with the use of single chain antibody fragments of the Pbs 21 gene. The single chain bound to $P$. berghei ookinetes and blocked oocyst development by at least $93 \%$. Also Lal et al. (2001), working with different monoclonal antibodies against mosquito midguts have found that they displayed broadspectrum activity, blocking parasite development of both $P$. falciparum and $P$. vivax in different species of mosquito. Furthermore the monoclonals reduced the mosquito fecundity and survivorship what could be interesting, as the authors discussed, if one wants to use these candidates as transmission blocking vaccines (Lal et al. 2001).

\section{Perspectives}

In the present, the mosquito transformation is in a top developmental era. It took many years for scientists to find efficient transposable elements and suitable markers, to study and characterize strong promoters and to develop efficient microinjection techniques. Now, with all the tools in hand it was shown to be possible (Ito et al. 2002, Moreira et al. 2002) to achieve the major goal of the whole process: to obtain a less efficient vector mosquito. By having a refractory mosquito, other diseases that are increasing over the last years as virus-borne diseases (Enserink 2000) or parasitic worms (Ramaiah et al. 2000) could be controlled as well.

It is important now to focus for the discovery of different candidates as parasite blocking agents and moreover to have molecules with different mechanisms of action in order to target different stages of Plasmodium without interfering, if possible, with the mosquito fitness.

Although great achievements with the mosquito transgenesis have occurred, the next steps towards the release of these mosquitoes into wild populations still lack studies.
Besides these issues, one point of great importance is to obtain the proof that these engineered organisms would neither be harmful to the environment nor to human beings in order to mitigate the skepticism against GMOs (Genetic Modified Organisms). Also, political issues have to be clarified for the success of any insect releasing program.

If no success is achieved with the use of transgenic mosquitoes for vector borne diseases control, at least the technique could show how powerful this approach can be for studying the interaction between the parasites and their vectors.

\section{Acknowledgments}

We thank Dr. Antônio R. Panizzi for the invitation to write this Forum article. Part of the work cited on this review was accomplished by supports of the National Institute of Health (N.I.H, USA), and the World Health Organization (WHO).

\section{Literature Cited}

Allen, M.L., D.A. O'Brochta, P.W. Atkinson \& C.S. Levesque. 2001. Stable, germ-line transformation of Culex quinquefasciatus (Diptera: Culicidae). J. Med. Entomol. 38: 701-10.

Atkinson, P.W., A.C. Pinkerton \& D.A. O'Brochta. 2001. Genetic transformation systems in insects. Annu. Rev. Entomol. 46: 317-346.

Berghammer, A.J., M. Klingler \& E.A. Wimmer. 1999. A universal marker for transgenic insects. Nature 402: 370371.

Breman, J.G. 2001. The ears of the hippopotamus: manifestations, determinants, and estimates of the malaria burden. Am. J. Trop. Med. Hyg. 64: 1-11.

Capurro, M. de L., J. Coleman, B.T. Beerntsen, K.M. Myles, K.E. Olson, E. Rocha, A.U. Krettli \& A.A. James. 2000. Virus-expressed, recombinant single-chain antibody blocks sporozoite infection of salivary glands in Plasmodium gallinaceum-infected Aedes aegypti. Am. J. Trop. Med. Hyg. 62: 427-433.

Cary, L.C., M.J. Goebel, B. Corsaro, H.G. Wang, E. Rosen \& M.J. Fraser. 1989. Transposon mutagenesis of baculoviroses: analysis of Trichoplusia ni transposon IFP2 insertions within the FP-locus of nuclear polyhedrosis viruses. Virology 172: 156-169.

Catteruccia, F., T. Nolan, T.G. Loukeris, C. Blass, C. Savakis, F.C. Kafatos \& A. Crisanti. 2000. Stable germline transformation of the malaria mosquito Anopheles stephensi. Nature 405: 959-962.

Coates, C.J., N. Jasinskiene, G.B. Pott \& A.A. James. 1999. Promoter-directed expression of recombinant fire-fly luciferase in the salivary glands of Hermes-transformed 
Aedes aegypti. Gene 226: 317-325.

Coates, C.J., N. Jasinskiene, L. Miyashiro \& A.A. James. 1998. Mariner transposition and transformation of the yellow fever mosquito, Aedes aegypti. Proc. Natl. Acad. Sci. USA 95: 3748-3751.

Cornel, A. J., M.Q. Benedict, C.S. Rafferty, A.J. Howells \& F.H. Collins. 1997. Transient expression of the Drosophila melanogaster cinnabar gene rescues eye color in the white eye (WE) strain of Aedes aegypti. Insect Biochem. Mol. Biol. 27: 993-997.

Enserink, M. 2000. New York's deadly virus may stage a comeback. Science 287: 2129-2130.

Edwards, M.J., F.J. Lemos, M. Donnelly-Doman \& M. JacobsLorena. 1997. Rapid induction by a blood meal of a carboxypeptidase gene in the gut of the mosquito Anopheles gambiae. Insect Biochem. Mol. Biol. 12: 1063 1072 .

Edwards, M.J., L.A. Moskalyk, M. Donelly-Doman, M. Vlaskova, F.G. Noriega, V.K. Walker \& M. JacobsLorena. 2000. Characterization of a carboxypeptidase A gene from the mosquito, Aedes aegypti. Insect Mol. Biol. 9:33-38.

Franz, G. \& C. Savakis, C. 1991. Minos, a new transposable element from Drosophila hydei, is a member of the Tc-1like family of transposons. Nucl. Acids Res. 19: 6646.

FUNASA. 2002. Situação da prevenção e controle das doenças transmissíveis no Brasil. Ministério da Saúde, Brasilia, DF, 45p.

Ghosh, A., M.J. Edwards \& M. Jacobs-Lorena. 2000. The journey of malaria in the mosquito: hopes for the new century. Parasitol. Today 16: 196-201.

Ghosh, A.K., P.E. Ribolla \& M. Jacobs-Lorena. 2001. Targeting Plasmodium ligands on mosquito salivary glands and midgut with a phage display peptide library. Proc. Natl. Acad. Sci. USA. 98: 13278-13281.

Grossman, G.L, C.S. Rafferty, J.R. Clayton, T.K. Stevens, O. Mukabayire \& M.Q. Benedict. 2001. Germline transformation of the malaria vector, Anopheles gambiae, with the piggyBac transposable element. Insect. Mol. Biol. 10: 597-604.

Grossman, G.L., C.S. Rafferty, M.J. Fraser \& M.Q. Benedict. 2000. The piggyBac element is capable of precise excision and transposition in cells and embryos of the mosquito, Anopheles gambiae. Insect. Biochem. Mol. Biol. 30: 909914.

Handler, A.M. 2000. An introduction to the history and methodology of insect gene transfer, p. 3-26. In A.M.
Handler \& A.A. James (eds.), Insect transgenesis: methods and applications. CRC Press, Boca Raton, FL, $376 \mathrm{p}$.

Handler, A.M. \& R.A. Harrell II. 1999. Germline transformation of Drosophila melanogaster with the piggyBac transposon vector. Insect Mol. Biol. 8: 449-57.

Horn, C., B. Jaunich \& E.A. Wimmer. 2000. Highly sensitive, fluorescent transformation marker for Drosophila transgenesis. Dev. Genes Evol. 210: 623-629.

Ito, J., A. Ghosh, L.A. Moreira, E.A. Wimmer \& M. JacobsLorena. 2002. Transgenic anopheline mosquitoes impaired in transmission of a malaria parasite. Nature 417:452-455

Jasinskiene, N., C.J. Coates \& A.A. James. 2000. Structure of Hermes integrations in the germline of the yellow fever mosquito, Aedes aegypti. Insect Mol. Biol. 9: 11-8.

Jasinskiene, N., C.J. Coates, M.Q. Benedict, A.J. Cornel, C.S. Rafferty, A.A. James \& F.H. Collins. 1998. Stable transformation of the yellow fever mosquito, Aedes aegypti, with the Hermes element from the housefly. Proc. Natl. Acad. Sci. USA 95: 3743-3747.

Kokoza, V., A. Ahmed, E.A. Wimmer \& A.S. Raikhel. 2001. Efficient transformation of the yellow fever mosquito Aedes aegypti using the piggyBac transposable element vector $\mathrm{pBac}[3 \mathrm{xP3}$-EGFP afm].Insect Biochem. Mol. Biol. 31: $1137-1143$.

Kokoza, V., A. Ahmed, Wen-Long Cho, N. Jasinskiene, A.A. James \& A. Raikhel. 2000. Engineering blood mealactivated systemic immunity in the yellow fever mosquito Aedes aegypti. Proc. Natl. Acad. Sci. USA 97: 9144-9149.

Lal A.A., P.S. Patterson, J.B. Sacci, J.A.Vaughan, C. Paul, W.E. Collins, R.A. Wirtz \& A.F. Azad. 2001. Antimosquito midgut antibodies block development of Plasmodium falciparum and Plasmodium vivax in multiple species of Anopheles mosquitoes and reduce vector fecundity and survivorship. Proc Natl Acad Sci USA. 98: 5228-5233.

McGrane, V., J.O. Carlson, B.R. Miller \& B.J. Beaty. 1988. Microinjection of DNA into Aedes triseriatus ova and detection of integration. Am. J. Trop. Med. Hyg. 39: 502510 .

Medhora, M., K. Maruyama \& D.L. Hartl. 1991. Molecular and functional analysis of the mariner mutator element Mos1 in Drosophila. Genetics 128: 311-318.

Miller, L.H., R.K. Sakai, P. Romans, R.W. Gwadz, P. Kantoff \& H.G. Coon. 1987. Stable integration and expression of a bacterial gene in the mosquito Anopheles gambiae. Science 237: 779-781. 
Moreira L.A., J. Ito, A. Ghosh, M. Devenport, H. Zieler, E.G. Abraham, A. Crisanti, T. Nolan, F. Catteruccia \& M. Jacobs-Lorena. 2002. Bee venom phospholipase inhibits malaria parasite development in transgenic mosquitoes. J Biol Chem. 277: 40839-40843.

Moreira, L.A., M.J. Edwards, F. Adhami, N. Jasinskiene, A.A. James \& M. Jacobs-Lorena. 2000. Robust gutspecific gene expression in transgenic Aedes aegypti mosquitoes. Proc. Natl. Acad. Sci. USA 97: 1089510898.

Morris, A.C. 1997. Microinjection of mosquito embryos, p. 423-429. In J.M. Crampton, C.B. Beard \& C. Louis (eds.), The molecular biology of insect vectors of disease. London, Chapman \& Hall, 604p.

Morris, A.C., P. Eggleston \& J.M. Crampton. 1989. Genetic transformation of the mosquito Aedes aegypti by microinjection of DNA. Med. Vet. Entomol. 3: 1-7.

Nolan, T., T.M. Bower, A.E. Brown, A. Crisanti \& F. Catteruccia. 2002. PiggyBac-mediated germline transformation of the malaria mosquito Anopheles stephensi using the red fluorescent protein dsRED as a selectable marker. J. Biol. Chem. 277: 8759-8762.

Perera, O.P., R.A. Harrell \& A.M. Handler. 2002. Germ-line transformation of the South American malaria vector, Anopheles albimanus, with a piggyBac/EGFP transposon vector is routine and highly efficient. Insect Mol. Biol. 11:291-297.

Pinkerton, A.C., K. Michel, D.A. O'Brochta \& P.W. Atkinson. 2000. Green fluorescent protein as a genetic marker in transgenic Aedes aegypti. Insect. Mol. Biol. 9: 1-10.

Ramaiah, K.D., P.K. Das, E. Michael \& H. Guyatt. 2000. The economic burden of lymphatic filariasis in India. Parasitol. Today 16: 251-253.

Rubin, G.M. \& A.C. Spradling. 1982. Genetic transformation of Drosophila with transposable element vectors. Science 218: 348-353.

Service, M.W. 1993. Mosquitoes (Culicidae), p. 120-240. In R.P. Lane \& R.W. Crosskey (eds.), Medical insects and arachnids. London, Chapman \& Hall, 744p.

Warren, W.D., P.W. Atkinson \& D.A. O'Brochta. 1994. The Hermes transposable element from the house fly, Musca domestica, is a short inverted repeat-type element of the hobo, Ac, and Tam3 (hAT) element family. Genet. Res. Camb. 64: 87-97.

World Bank Report, 2001. Malaria at a Glance. http:// rbm.who.int/cmc_upload/0/000/014/813/ Malaria_at_a_glance1. $\bar{h}$ tm

Yoshida, S., H. Matsuoka, E. Luo, K. Iwai, M. Arai, R.E. Sinden \& A. Ishii. 1999. A single-chain antibody fragment specific for the Plasmodium berghei ookinete protein $\mathrm{Pbs} 21$ confers transmission blockade in the mosquito midgut. Mol. Biochem. Parasitol. 104: 195-204.

Zieler, H., D.B. Keister, J.A. Dvorak \& J.M. Ribeiro. 2001. A snake venom phospholipase A(2) blocks malaria parasite development in the mosquito midgut by inhibiting ookinete association with the midgut surface. J. Exp. Biol. 204: 4157-4167. 